\section{Foundation net to be widened for future prizes}

Bern

SustaInED by the fortune of an antifascist publisher who fled from Italy in 1933, the Balzan Foundation is doing what it can to secure recognition for its prizes, awarded annually since 1978 , as complements to the Nobel prizes. At the awards ceremony here on 13 November, officials of the foundation made it clear that they wish to cast their net wider than Italy and Switzerland, where the Balzan prizes have so far attracted most attention.

This year's prizes (see Nature 329, 279; 1987) went to a physical anthropologist, a human psychologist and a mediaeval historian. Each recipient will receive 250,000 Swiss francs (roughly $\$ 180,000)$ to use as help recipients "enrich their students".

The prizes are given specifically in areas not covered by the Nobel prizes and which are identified in advance. The 1988 prizes, which will be awarded in Rome, will be in the fields of applied botany, sociology and comparative literature. The value of the prizes will increase in 1988 to SFr 300,000 . Every third year, there will be a peace prize.

South African physical anthropologist Phillip Tobias, 62, head of the Department of Anatomy at the University of the Witwatersrand, was selected for his contributions to the study of early hominids. Tobias intends to use his prize for "some type of educational foundation to provide facilities for underprivileged students in South Africa".

Jerome Bruner, 72, divides his time between Harvard University and the New School for Social Research in New York. he likes. The prizes are also intended to

A wealth of prizes awarded this week. Top: Drs Jerome $S$. Bruner, Richard Southern and Phillip V. Tobias, winners of the Balzan Foundation awards. Bottom: Professors Morris Cohen and Jan Hendrik Oort, recipients of the Kyoto prizes and Gerald F. Tape, winner of one of the Fermi awards.



Bruner is known as a cognitive psychologist. He was an early opponent of behaviourism. He is among those psychologists who assert that the development of a child reflects the culture and values with which he or she is surrounded. In a celebrated experiment in the early 1960s, he asked children from poor and rich families to judge the size of a dollar coin; the poorer children judged it to be larger.

British mediaeval historian Sir Richard Southern, of Oxford, the third recipient, has distinguished himself in his easy-toread yet widely respected accounts of the religious and intellectual development of Europe in the Middle Ages.

Balzan, a publishing magnate, died in Switzerland in 1953 without leaving a will. The foundation was established in 1957 in settlement of a dispute between Italian and Swiss authorities, who disagreed about whether the Balzan fortune should revert to Italy upon the death of Angela Balzan, Eugenio's daughter and sole heiress. This is why the organization is actually a dual one, with the prizewinners sclected by the Milan branch and the money managed by the Zurich branch.

Steven Dickman

\section{Fermi awards for atomic energy advances}

San Francisco

THE US Department of Energy (DoE) has chosen a researcher and an administrator to receive the 1987 Enrico Fermi Awards. Luis W. Alvarez and Gerald F. Tape will each receive $\$ 100,000$, a gold medal and a presidential citation.

The Fermi awards have been given each year since 1954 to honour scientific and technical achievement in the development, use or control of atomic energy.

Tape, 72, is past president of Associated Universities Inc., a non-profit organization that manages Brookhaven National Laboratory and the National Radioastronomy Observatory. His award acknowledges his contributions to the advancement of nuclear power and the non-proliferation of nuclear weapons.

Tape served as the US representative to the International Atomic Energy Agency from 1973 to 1977 , and was instrumental in the implementation of the nuclear nonproliferation treaty.

Alvarez, 76, is professor emeritus of physics at the University of California at Berkeley and senior scientist at Lawrence Berkeley Laboratory. He received the 1968 Nobel prize in physics for his work on the development of the hydrogen bubble chamber and subsequent use of the bubble chamber to reveal previously unobserved, shortlived classes of subatomic particles.

The advance revolutionized the field of high-energy physics and eventually led to the quark model, the currently accepted description of sub-atomic matter.

The awards will be presented at a ceremony in Washington in December.

Marcia Barinaga

\section{Prizegiving season arrives}

\section{Tokyo}

IT is the season for Japan to give away big money prizes to scientists. Last week it was the Kyoto prize and Honda prize, next week the International prize for Biology

Professor Jan Hendrick Oort, 87, of the Netherlands, and Professor Morris Cohen, 75, of the United States, are the two scientists among this year's three winners of the Kyoto prize. The prize was set up in 1985 by Kazuo Inamori, founder of Kyocera Corporation, a fast-growing ceramics manufacturer. Recipients must be people who "are sensitive to their own human fallibility, and who have a deeply rooted reverence for the universal spirit". Oort's reverence for the Universe has no doubt increased - he gets his $¥ 45$ million $(\$ 330,000)$ prize for elucidating the structure and dynamics of the Galaxy - while Cohen is rewarded for developing new materials, like ultra-high strength steels, shape-memory alloys and ceramics.

The Honda prize, awarded by a foundation set up by Honda Motor Company, is given to individuals or organizations that promote "ecotechnology". According to the foundation, this means technology that "harmonizes the overall environment of human activity". This year"s award of $¥ 10$ million $(\$ 75,000)$ goes to Professor Jean Dausset, 71 , of the Collège de France in Paris. Dausset received the Nobel prize for Medicine in 1980 and has promoted a worldwide group called the "Universal Movement of Scientific Responsibility".

The International prize for Biology was established in 1985 to celebrate the sixtieth anniversary of the Emperor's accession to the throne, and is intended to become Japan's "Nobel prize" of biology. The $¥ 10$ million prize goes to Professor John Bertrand Gurdon of Cambridge University, who is best known for his demonstration in the 1970 s that it is possible to clone frog (Xenopus) eggs.

David Swinbanks 